\title{
Research on Accounting and Application of University Digital Assets Wei-guo KANG
}

\author{
Finance Department of Nanjing University of Finance and Economics, Nanjing, China
}

\begin{abstract}
Keywords: Digital Asset; Accounting; Measurement Basis; Value-added Development.
\end{abstract}
\begin{abstract}
As the most important institution for knowledge creation, colleges and universities have accumulated a large number of digital assets under the support of information technology such as big data and cloud computing. However, current academic research on university digital assets mainly focuses on the formation process and management development. There are few studies on the accounting of digital assets in colleges and universities. This paper focuses on the analysis of the concept, characteristics and classification of university digital assets, and introduction of accounting of university digital assets. Finally, the conclusions are drawn and the development and application of university digital assets are forecasted.
\end{abstract}

\section{Introduction}

Drawing upon extensive literature review, this paper first expounds the basic concept of university digital assets, analyzes the characteristics, and makes a classification. Second, starting from the distinctiveness of university digital assets, it describes recognition conditions, measurement basis, accounting records and report disclosure in detail, and constructs a relatively sound accounting framework for digital assets, hoping to promote the construction of digital assets-related accounting system, in order to adapt to the rapidly changing economic environment. Finally, this paper provides some suggestions for further developing digital assets for better shared and value-added services.

\section{The Concept, Characteristics and Classification of University Digital Assets}

\subsection{The concept of university digital assets}

Digital assets are the product of the information process. Colleges and universities have accumulated rich information resources in teaching, scientific research and management activities, and through collecting, sequencing, storing and retrieving valuable information, asset-oriented information resources have been formed, namely, digital assets.

Based on the concept of digital assets, this paper makes a definition of university digital assets that refers to digital contents owned and controlled by universities which are accumulated through teaching, scientific research and management activities after a series of processing, and can be preserved and utilized. They not only have a digital form, but also conform to the basic characteristics of assets:

(1) They are generated from the teaching, scientific research, and management of the university or its members.

(2) The ownership and control rights belong to the university or its members.

(3) They can bring economic benefits to the university. However, it should be emphasized that, given the special nature of universities, digital assets are not directly invested in production activities. Therefore, the inflows of economic benefits brought by university digital assets are usually indirect. But this indirectness does not change the essential attributes of assets.

There are two concepts of university digital assets in narrow and broad sense. In a narrow sense, university digital assets refer to the information resources that have been preserved and utilized by universities in the academic research, administrative management, and classroom teaching activities. In the broad sense, university digital assets, in addition to the narrow concept, include digital assets purchased from outside, such as computing model, software resources, experimental data, etc. This paper mainly studies the narrow sense of university digital assets. 
University digital assets are essentially asset-oriented information resources, collecting, sequencing, storing, retrieving and managing valuable digital resources, which is the process of transforming digital resources into assets. In other words, digital assets are essentially digital forms of knowledge assets and information resources.

\subsection{Characteristics of university digital assets}

The main characteristics of university digital assets can be summarized as follows:

\subsubsection{Dependency}

Dependency includes two meanings. Firstly, viewing from the existence form, digital assets cannot exist independently. It must depend on some medium. Secondly, in terms of the content, digital assets must be combined with knowledge assets, information assets, data assets and so on to create higher values.

\subsubsection{Exclusive property rights}

From what have discussed above, digital assets are essentially digital forms of knowledge assets and data assets and so on. Therefore, digital assets also have exclusive property rights. Universities have independent property rights in their digital assets. Any organization or individuals shall not occupy or use the assets in any way without the permission of the right-holder.

\subsubsection{Content Sharing}

Digital assets are essentially asset-oriented information resources. The transfer and use of data assets are essentially the exchange of information that neither wastes assets nor generates costs. The result of the exchange is the content sharing of the digital asset, which can be replicated and reused indefinitely.

\subsubsection{Value-added}

Digital assets can be replicated indefinitely, but the marginal cost is zero, that is, the total production cost remains unchanged. Normal exchange and sharing do not waste digital assets. It simply transfers from one medium to another. Therefore, under the condition of constant costs, digital assets can help develop implicit knowledge, create new assets, and bring value increment in the process of exchange and sharing.

\subsection{Classification of university digital assets}

University digital assets can be classified into several types according to different criteria.

(1) According to the function, university digital assets can be classified into the type of education, the type of knowledge exploration, research achievement, technology development, product invention, theoretical innovation, and practice data, etc.

(2) According to the content, university digital assets can be classified into three categories: academic research, education and teaching, and administrative management. The digital assets of academic research mainly include all kinds of research achievements, such as the project report formed in the initial stage, the calculation model in the process of research, experimental data, the final report at the end of the project, journal papers, technical patents, and monographs, etc. According to the teaching form, the digital assets of education and teaching can be classified into three types: classroom teaching, in-class experimental teaching and out-of-class practical teaching. Administrative digital assets are mainly reflected in the administrative approval documents related to the decisions of universities and the internal rules and regulations.

(3) According to the asset management, university digital assets can be classified into four types: information assets, data assets, knowledge assets and archive assets. Information assets are digital contents that have been preserved and utilized in universities' academic research, administrative management and teaching activities, including pictures, teaching courseware, and experimental data, which are "original" assets that have not yet been developed and managed. Data assets mainly refer to experimental data and computational models generated in universities' scientific research activities, which have obvious potential value. Knowledge assets refer to intellectual assets or business activity products that can bring benefits, such as patents, copyrights, or intellectual 
property. Archive assets are digital archives formed based on the requirements of archives management, which are produced in teaching, academic research and management in universities.

\section{Accounting of University Digital Assets}

\subsection{Accounting recognition of university digital assets}

Assets in accounting standards are clearly defined as resources owned or controlled by enterprises due to past transactions or events, and are expected to generate economic benefits for enterprises. Although differing from tangible assets, digital assets can bring indirect inflows of benefits to universities and reasonably estimate the costs. Therefore, digital assets should also be recognized and measured as a special asset of universities.

Due to the dependency talked above, digital assets cannot exist independently, which must depend on intangible assets such as knowledge assets. But digital assets are by no means equivalent to intangible assets.

First of all, digital assets are intangible which depend on some medium. Secondly, as mentioned above, due to the special nature of universities, digital assets are not directly invested in production activities, which cannot bring direct inflows of economic benefits. But this does not change the essential attributes of assets. Finally, the cost of digital assets can be reasonably estimated. The actual value of digital assets can be estimated based on the expenditure under development or the present value of inflows of economic benefits for universities in the future.

Digital assets are both property exclusive and content-sharing, which digitize knowledge assets to provide people with high-quality value-added services through information technology, such as information diversion and data association. Intangible assets do not have shared content. No one shall occupy and use intangible assets without the permission of the owner who shall enjoy the benefits from intangible assets.

Therefore, based on the characteristics of digital assets, it is recommended to set up a new general ledger account titled "Digital Assets" under asset accounts to record changes in digital assets. At the same time, two subsidiary accounts are set up, namely, "Provision for Impairment of Digital Assets" and "Accumulated Amortization of Digital Assets". Universities can enjoy the services provided by digital assets within a certain period of time. Therefore, the cost of digital assets should be amortized during the benefit period. In addition, "Provision for Impairment of Digital Assets" records the impairment due to potential factors (i.e. recoverable amount of digital assets is lower than book value).

\subsection{Measurement basis of university digital assets}

From what have discussed above, university digital assets, according to the function, can be classified into the type of education and teaching, the type of knowledge exploration, research achievement, technology development, product invention, theoretical innovation, and fact data, etc.

When measuring assets, there are two kinds of value bases: input value and output value. Input value refers to the cost of acquiring assets, including historical cost, current cost and replacement cost. Both fixed assets and intangible assets are measured on the basis of historical cost. Historical cost data are easily obtained, and the authenticity of book value of assets can be verified by comparing original vouchers. Output value is based on the economic inflows from the exchange of assets which eventually separate from the organization, including the current market value, net realizable value, liquidation value and present value of future cash flows, etc.

The author believes that different value bases should be used to measure university digital assets according to their classifications. Digital assets of research achievement, technology development and product invention should be measured by present value of future cash flows. In the current accounting environment, it is possible to reasonably estimate the future economic benefits brought by such "result-based" digital assets through certain technical means. Many of the intellectual assets used in the development of digital assets are not measurable by market value. The investment of calculable tangible capital may be very limited. It cannot reasonably reflect the actual value of the 
asset by using the historical cost. Therefore, the present value of future cash flows should be employed to measure the actual value of such digital assets, which takes into consideration both the current risks and the time distribution of the inflows of economic benefits brought by digital assets.

For digital assets of education and teaching, knowledge exploration, theoretical innovation, and fact data, they should be measured with the historical cost. The inflows of economic benefits brought by university digital assets are usually indirect. It is impossible to measure the present value by estimating the economic inflows and time distribution. Therefore, the historical cost should be used for measurement.

\subsection{The framework of accounting of university digital assets}

\subsubsection{Acquisition of Digital Assets}

The initial measurement takes the actual value of digital assets as the initial entry cost, debiting the "digital assets" and crediting the "bank deposits" account. As mentioned above, for digital assets of research achievement, technology development and product invention, their actual value, as the initial entry cost, should be reasonably measured, taking into account the current risks and the time distribution of the inflows of economic benefits. For digital assets of education and teaching, knowledge exploration, theoretical innovation, and fact data, the entry value includes all development costs in the research and development phase and a series of expenses (including technical processing fees, patent registration fees, etc.) generated in the process of information resources becoming assets.

\subsubsection{Impairment of Digital Assets}

If the digital assets are replaced by more optimized technology, models, data and other achievements, and they cannot bring economic benefits to universities, in this case, it requires the provision for impairment of digital assets. To reflect the actual value, it is necessary to recalculate the value of digital assets in accordance with the future cash flows under the current risk conditions, and compare the book value with the actual value of the recalculated assets. When the actual value of assets is lower than book value, according to the balance, it shall debit the "asset impairment loss" and credit the "provision for impairment of digital assets" account. When the actual value of assets is higher than book value, no adjustment shall be made according to the principle of prudence.

\subsubsection{Amortization of Digital Assets}

Digital assets can provide services for universities in a period of time. According to the matching principle of income and cost, the cost of digital assets shall be amortized over the benefit period. For digital assets of scientific research, technology development and product invention, the method of accelerated amortization should be adopted, such as double declining balance method and sum-of-the-years-digits method (SYD). The higher the income, the higher the cost of digital asset amortization; the lower the income, the lower the cost of amortization, thus rationalizing the cost amortization and distribution.. At the final amortization, it shall debit the "administrative expense" and credit the "digital assets amortization" account. For digital assets of theoretical innovation and fact data, due to their uncertain income method and slow update, no amortization shall be made like intangible assets, but at least test the asset impairment at the end of each year. If the actual value of the asset is lower than book value, provision for impairment shall be made and included in the current profit and loss. If the actual value is higher than book value, no adjustment shall be made according to the principle of prudence.

\subsubsection{Value Increment of Digital Assets}

The formation of digital assets is a process of continuous improvement. To maintain the advancement of theory or technology, scholars should constantly carry out field observation, empirical research, development and theoretical innovation. Therefore, the recognition of digital assets is continuous, which is similar to the expansion and improvement of fixed assets. The book value of digital assets should be increased according to the subsequent research and development costs, and the amortization period and method should be readjusted. 


\subsubsection{Report of Digital Assets}

As an important asset of universities, according to the principle of importance, digital assets should be properly disclosed in the accounting report. First of all, "digital assets" should be added under the non-current asset account in the balance sheet to disclose the book value. Besides, detailed information of digital assets should also be disclosed in accounting statements note, including the main factors affecting the entry value, namely the expected future cash flows and discount rate, the main factors affecting the amortization and the reasons for choosing the amortization method. In addition, the risks faced by digital assets should be disclosed. If the developed digital assets are replaced by better technology, data, models, etc., the value of the digital assets will be greatly reduced. Therefore, the risks faced by current digital assets should be properly disclosed.

\section{Development and Application of University Digital Assets}

With the maturity of internet technology such as cloud computing and big data, people have entered a new era of digital assets. Through the development and utilization of university digital assets, it can better serve teaching and scientific research activities, and help explore implicit knowledge, create new assets, and bring value increment in exchanges.

The clear ownership of digital assets in universities is an important basis for value-added development to provide high-quality shared services. Universities should do a good job in the copyright protection and management of digital assets. For the copyright management of published works (including academic papers published in journals by teachers and students), a special copyright database should be established to record the copyright information, so as to avoid copyright disputes. For unpublished works, universities should get the authorization of the author or a third party and sign a copyright license agreement with them to obtain the right of reproduction and internet communication.

Through the clustering of university digital assets and its integration with library resources, a huge database has formed, which provides the resource basis for the development of digital assets. Besides, data processing technology, such as cloud computing, is a powerful tool for the value-added development of university digital assets. Universities must improve and innovate the management methods of digital assets so as to enhance their value, such as splitting, refining, and restructuring digital assets. By restructuring the contents of digital assets, special data, information and knowledge can be formed. For example, teaching assets in universities include curriculum introduction, syllabus, PPT, and references and so on. These teaching assets can be used independently or in combination with each other. By integrating these teaching assets according to subjects, taking public class videos, recording audio, and inserting PPT and subtitles, high-quality public video classes are formed, which are new assets generated from the combination of various teaching assets. They can better provide teachers and students with open services for learning resources.

\section{Acknowledgement}

This research was financially supported by the Project of Nanjing University of Finance and Economics "Research on the Accounting and Application of Digital Assets in Colleges and Universities".

\section{References}

[1] Ministry of Finance. Accounting Standard for Business Enterprises. Beijing: Economic Science Press, 2006.

[2] Institute of Economic Chinese Academy of Social Sciences. Dictionary of Modern Economics. Nanjing: Phoenix Publishing House; Jiangsu People's Publishing House, 2005, pp. 1282. 
[3] Y.Q., Lv et al. Accounting Recognition and Measurement of Digital Assets. Journal of Central University of Finance \& Economics, Vol. (11), 2003, pp. 62-65.

[4] K.L., Wang. The Economic Characteristics, Classification and Pricing Strategy of Digital Products. China Soft Science, Vol. (6), 2002, pp. 58-62.

[5] R., Yuan and S., Liang. Formation and Management Strategies for University Digital Assets. Library and Information Service, Vol. (12), 2012, pp. 43-49.

[6] R., Yuan, S., Liang and Z.X., Wang. Research on Process Management of University Digital Assets. Research on Library Science, Vol. (1), 2013, pp. 68-72.

[7] Q., Fu and R., Yuan. Research on the Value-added Development of University Digital Assets Based on Pyramid Model. Research on Library Science, Vol. (1), 2013, pp. 88-92.

[8] Conway P. Modeling the Digital Content Landscape in Universities. Library Hi Tech, Vol. 26 (3), 2008, pp. 342-354.

[9] Gerrit Tamm and Oliver Gunther. Business Models for ASP Marketplaces. Proceedings 12th European Conference on Information Systems, 2000.

[10] Hui, Kai Lung and Patrick YK Chau. Classifying Digital Products. Communications of the ACM, Vol. 45 (6), 2002, pp. 73-79.

[11] Y.S., Wang, Tzung-I. Tang and Jeung-tai Eddie Tang. An Instrument for Measuring Customer Satisfaction toward Websites that Market Digital Products and Services. Journal of Electronic Commerce Research, Vol. 2 (3), 2001, pp. 89-102. 